\title{
Long-term Monitoring of Environmental Changes along China-Europe Railway Express (CER Express) using Multi-Source Remotely Sensed Data
}

\author{
Bohong Ma ${ }^{1}$, Xian Guo ${ }^{1}$ *, Jie Jiang ${ }^{1}$, Dubravko Culibrk ${ }^{2}$, Shuai Ding ${ }^{1}$, Marko Vilotic ${ }^{2}$, Yang Li $^{1}$ \\ ${ }^{1}$ Beijing University of Civil Engineering and Architecture (BUCEA), Beijing, China, lucky9851@sina.com, (guoxian, jiangjie, \\ dingshuai, liyang)@bucea.edu.cn \\ ${ }^{2}$ University of Novi Sad, Novi Sad, Serbia, (dculibrk, markovil)@uns.ac.rs
}

Commission II, III/IVc

KEY WORDS: Environmental monitoring, Multi-source, China-Europe Railway Express (CER-Express), Sustainable development

\begin{abstract}
:
The China-Europe Railway Express (CER-Express), not only promoted the cooperation between countries and regions across Asia and Europe but also gave rise to remarkable changes in landcover and had a profound effect on the natural environment along the railway in recent years. Effective ways to monitor and assess ecological changes are urgently needed to ensure sustainable development of CER-Express. There are very few existing environmental monitoring studies focusing on the area along the CERExpress. In this paper, we present a study of environmental degradation, which occurred during the construction and operation of CER-Express from 2010 to 2018, based on a comprehensive evaluation index (CEI), which takes three environmental indicators into account and provides a timely and reliable evaluation of environmental changes at large scales. In addition, the environment conditions of the regions and countries along the CER-Express have been quantified and comparatively studied at different scales over different periods, using histograms of mean CEI values. Furthermore, specific causes of environmental degradation in the railintensive countries and small-area countries along the railway are discussed. Our results show that the environmental degradation can be detected in most of the rail-intensive countries, such as Germany, Poland, Austria, and Czech Republic along the railway. Therefore, to ensure sustainability of the CER-Express, environmental protection along the railway should be paid more attention to and a reasonable arrangement for the exploitation of CER-Express devised.
\end{abstract}

\section{INTRODUCTION}

The CER-Express is of great significance in promoting the trade between East and West, since it is strengthening the cooperation between countries along the railway. Until March 2020, more than 21,000 China-Europe trains were operated, reaching 18 countries and 57 cities in Europe (Zhang 2020), bringing a positive, profound impact on resource allocation and economic growth (Xu 2020).

Since the Goal 15 was mentioned in the Sustainable Development Goals (SDGs) proposed by United Nations (UN), many studies have explored the worldwide environmental issues involved in the sustainability of terrestrial ecosystems, desertification, and land degradation (Kavvada, Metternicht et al. 2020), whereas very little research has been done on the topic along the China-Europe Railway Express (CER-Express). Intensively constructed transportation network and the operation of CER-Express gradually imposed unprecedented pressure on the local ecological environment in the regions along the railway (Hafeez, Yuan et al. 2020), leading to degradation, including land degradation, vegetation habitat fragmentation, biodiversity reduction, and ecosystem degradation, etc. (Ascensão, Fahrig et al. 2018).

Remote sensing (Chen, Chuvieco et al. 2021) is an effective tool for Earth Observation (EO) and can be used to detect spatial variations across large regions on multiple scales. In literature, it is commonly used to evaluate environmental changes, such as atmosphere pollution ( $\mathrm{Wu}$, Zhang et al. 2020), deforestation (Griffiths, Jakimow et al. 2018), and urban development on scales ranging from countrywide to the worldwide.

In general, two strategies were commonly used to estimate the environmental degradation by remote sensing datasets. In the single-indicator analysis methodology, the indicators used in existing studies were related to either the natural environment or socioeconomic aspect, such as the PM2.5 indicator (Meng, Liu et al. 2021), the vegetation denseness indicator (Qi, Jia et al. 2019), urban development indicator (Chen, Sui et al. 2019) etc. However, in large regions, such as the regions along the One Belt One Road (OBOR), the environment conditions vary due to joint action of numerous factors. Thus, analyzing only a single indicator does not reveal the association between long timeseries of human activities and caused comprehensive environmental changes.

The multi-parameter correlation analysis method uses not only the socio-human development indicators but also the ecological features, such as footprints, to evaluate the relationship between environmental changes and human activities (Fang, Wang et al. 2020) (Mariano, Santos et al. 2018) (Yang and $\mathrm{Hu} 2019$ ). This method allows us to identify the areas vulnerable to land degradation, the increase of this tendency due to human behavior and the consequences of degradation. Due to the regional differences along the CER-Express, the values and changes of indicators involved are quite different in each country along the CER-Express. Thus, this method could not be extended and applied to assess the ecological condition of the whole region along the CER-Express.

Previous studies have indicated that the development and urbanization occasionally caused a negative impact on the environment. For regions along the CER-Express, few studies focusing on long term environment monitoring and change evaluation have been conducted. This is especially true for the period after the CER-Express began its operation. In this study we use long-term multi-source datasets and histograms of mean comprehensive evaluation index (CEI) value, at different analysis scales, to accurately assess the environmental conditions along the CER-Express and briefly analyze the reasons of environment degradation in different regions and countries occurring during its fast construction and since the

${ }^{*}$ Corresponding author 
beginning of its operation.

We first selected long-time-series multi-source datasets (PM2.5, land surface temperature (LST), and normalized difference vegetation index (NDVI) dataset) as the main environment evaluation indicators. Their integrated index, CEI index was calculated to evaluate the ecological changes along the CERExpress (Europe section) from 2008 to 2018. To unveil the ecological changes in the study area and especially the regions near the CER-Express with the CEI index, three analysis scales are proposed, S1. entire countries along the CER-Express, S2. entire countries-not-along-the-railway with $S 3$. the 30 kilometers buffer zone along the CER-Express within each country. Finally, the mean CEI results at different scales were analyzed using histograms, to find the environmental degradation and main impact factors of it during the construction and operation of CER-Express.

At first, our study derived the CEI difference maps from 2010 to 2018 in the study area. Then three histograms of mean CEI values, which belong to the three scales were proposed to discover the impact of railway operation on the environment. Furthermore, the difference maps of three environmental factors were also derived to discuss the specific reason that caused the high level of environmental degradation in the rail-intensive countries and small-area countries along the railways. Our overall analyses revealed the correlation between the long-term human activities related to railway construction, operation and environment change along the CER-Express. Our research provides a scientific method for the evaluation of environmental degradation at large-spatial and long-temporal scale, that can be used to ensure sustainable development of the CER-Express in the future.

The rest of paper is organized as follows: Section 2 discusses the geography of the area studied and multi-source data acquired for the long-term monitoring along the CER-Express; Section 3 details the methodology of the data processing done and joint calculation required for CEI index; Section 4 analyzes the observed CEI values using histograms of mean CEI values at different scales. Section 5 discusses the specific causes of the environmental degradation in different regions along the railway. Section 6 concludes the paper with the summary of our overall findings and provides some directions for future work.

\section{STUDY AREA AND DATA}

\subsection{Study Area}

As shown in Fig.1, a total of 38 countries in Europe is involved, covering about 4,000,000 square kilometers. These are: Albania Andorra, Austria, Belarus, Belgium, Bosnia and Herzegovina, Bulgaria, Croatia, Czech Republic, Denmark, Estonia, France, Germany, Greece, Hungary, Ireland, Italy, Latvia, Liechtenstein, Lithuania, Luxembourg, Moldova, Monaco, Montenegro, Netherlands, North Macedonia, Poland, Portugal, Romania, Russian Federation, San Marino, Serbia, Slovenia, Slovakia, Spain, Switzerland, United Kingdom, Vatican City.

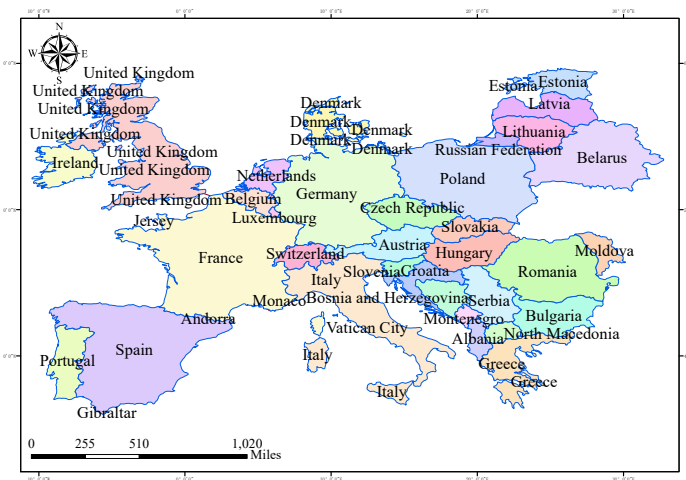

Fig. 1. Location of the study area

\subsection{Dataset}

2.2.1. PM2.5 Dataset: The particulate matter (PM2.5) dataset was obtained from the Atmospheric Composition Analysis Group at Dalhousie University by merging PM2.5 measurements from the European Environment Agency. The dataset was gridded at the finest resolution of the information sources that were incorporated $\left(0.01^{\circ} \times 0.01^{\circ}\right)$.

2.2.2. LST Dataset: To exclude solar interference, we used only nighttime averaged LST data. The LST data involved two types of data from the same sensor downloaded directly from NASA official website. MOD11A2 version 6 and MYD11A2 version 6 product provides an average of 8 days of land surface temperature and emissivity (LST\&E) with a spatial resolution of $1 \mathrm{~km}$.

2.2.3. NDVI Dataset: The monthly Terra Moderate Resolution Image (MODIS) was used to calculate the vegetation indicator (MOD13A3), which is provided at a spatial resolution of $1 \mathrm{~km}$. In this paper, the monthly average NDVI is used to calculate the VC indicator.

2.2.4. CER-Express Vector Line: The CER-Express (Europe Section) vector line was outlined with the ESRI official dataset (the accuracy was unknown) as the main dataset, supplemented by railway dataset from "Natural Earth" with the precision of $1: 10 \mathrm{~m}$, based on the reference site.

\section{METHODOLOGY}

The CEI has been shown as a valid index for the comprehensive assessment of environmental conditions in large scale areas $(\mathrm{Lu}$, Weng et al. 2019). The elements of the CEI involves three indices that have the most significant impact on the environmental quality, i.e., PM2.5, LST and NDVI. The calculation of CEI is formulated as below.

\subsection{Normalization of PM2.5}

The difference of PM2.5 in two years ( $P M^{I J}$ ) was converted to the normalized result ( Delta $P M$ ) through using Eqs. (1)-(2).

$$
\begin{gathered}
P M^{I J}=P M^{J}-P M^{I} \\
\text { Delta } P M=\frac{\left[\left(P M^{J}-P M^{I}\right)-\min P M^{I J}\right] * 100}{M a x P M^{I J}-M i n P M^{I J}}
\end{gathered}
$$

where Delta $P M=$ annual normalization difference result of the PM2.5 value between year $J$ and year $I$ 
$\operatorname{MaxPM}{ }^{I J}, \operatorname{MinP} M^{I J}=$ the largest and smallest PM2.5 difference value in the PM2.5 difference

\subsection{Normalization of LST}

The difference value of LST in two years( $L S T^{I J}$ ) was converted to the normalized result ( Delta $L S T$ ) through Eqs. (3)-(4).

$$
\begin{gathered}
L S T^{I J}=L S T^{J}-L S T^{I} \\
\text { Delta } L S T=\frac{\left[\left(L S T^{J}-L S T^{I}\right)-\min L S T^{L J}\right] * 100}{\operatorname{Max} L S T^{I J}-\operatorname{Min} L S T^{I J}}
\end{gathered}
$$

\subsection{Normalization of NDVI}

The difference value of NDVI in two years ( $\left.N D V I_{\text {nor }}^{X_{2}-X_{1}}\right)$ was converted to the normalized result (Delta $N D V I_{n o r}$ ) using Eqs. (5)-(6).

$$
N D V_{\text {nor }}^{X}=\left(N D V^{X}-N D V I^{X \min }\right) /\left(N D V^{X \max }-N D V^{X \min }\right)
$$

$$
N D V I_{n o r}^{X_{2}-X_{1}}=N D V I_{n o r}^{X_{2}}-N D V I_{n o r}^{X_{1}}
$$

where $\quad N D V I_{n o r}^{X}=$ the normalized result of NDVI at time $\mathrm{X}$ $N D V I_{\text {nor }}^{X_{2}-X_{1}}=$ the difference result of $N D V I_{n o r}^{X}$ in two years

$$
\text { Delta NDVI } I_{n o r}=\frac{\left[\operatorname{MaxNDVI} I_{\text {nor }}^{X_{2}-X_{1}}-N D V I_{\text {nor }}^{X_{2}-X_{1}}\right] * 100}{\operatorname{MaxNDVI} I_{\text {nor }}^{X_{2}-X_{1}}-\operatorname{MinNDVI}_{\text {nor }}^{X_{2}-X_{1}}}
$$

where Delta NDVI $I_{n o r}=$ the final normalized result of NDVI difference in two years

\subsection{CEI Index}

The CEI results were computed using the normalized results of PM 2.5 indicator, LST indicator and NDVI indicator.

$$
C E I=\sqrt[3]{(\text { DeltaP } M+1)^{*}(\text { DeltaLST }+1)^{*}\left(\text { Delta } N D V I_{n o r}+1\right)}
$$

The CEI index takes into account the air quality, intensity of human activity and damage to local vegetation over different periods, and provides an effective assessment of environmental change over a large area. A higher value of CEI stands for a higher level of local environmental degradation over a time period. As reported in the literature, the CEI ranges from 1 to 101, the positive correlation of it to the ecological footprint (EF) value was also proved ( $\mathrm{He}$, Gao et al. 2017). The correlation indicates the potential of CEI to evaluate the environment changes in large areas, such as the countries and the regions along the CER-Express.

\section{RESULTS}

In this part, the countries which contained equal or more than two CER-Express lines (Europe section) were defined "the railintensive countries". Using the area of Belarus as a standard, the countries which are several times $(<2)$ smaller will be defined the "small-area countries".

To analyze the ecological condition of the regions and countries along the CER-Express at first we demonstrated CEI results for the whole study area (the Europe region excluding Russia), with one map for each two-year period from 2008-2018 (Fig. 2). Then, we quantified and compared the variation of environment conditions at different scales (shown in Fig. 3 to Fig. 5) with the histograms of mean CEI values. Finally, in order to assess the impact of the operating of CER-Express on the ecological conditions in each country along the railway individually, two nationwide mean CEI values, $S 1$. the entire countries along the CER-Express (Fig. 3) with S2. the entire countries-not-alongthe-railway (Fig. 5) were calculated and compared. Moreover, to verify whether more significant environment degradation was present in the proximity of the railway, we further introduced region-wide mean CEI values of $S 3$. the 30 kilometers buffer zone along the CER-Express within each country (Fig. 4), the values were then compared to $\boldsymbol{S 1}$.

\subsection{CEI Results for the Europe Continent}

In this study, long-term CEI results for the study area (Europe continent) had been derived. Fig. 2 (a)-(e) show the CEI derived from 2010 to 2018 , produced in two-year increments. In the studied area, the blue regions represent less environmental degradation during the two-year period, while the red regions represent the areas where more degradation occurred. The CEI values in the region of Europe in all five subfigures range from 9.5 to 87. CEI values were high from 2008 to 2010 , then declined significantly from 2010 to 2012 . However, in the following years of high-speed construction and intensive operation of CER-Express, CEI values fluctuated continuously and were changing dramatically over time in different regions.

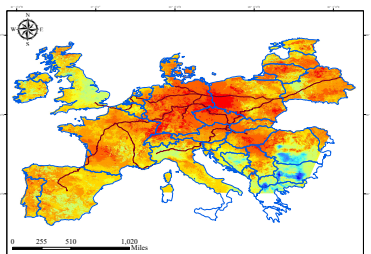

(a)

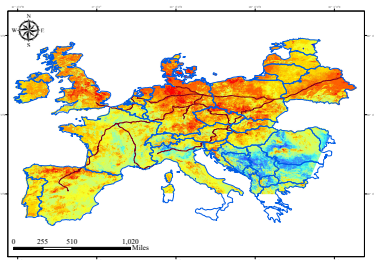

(c)

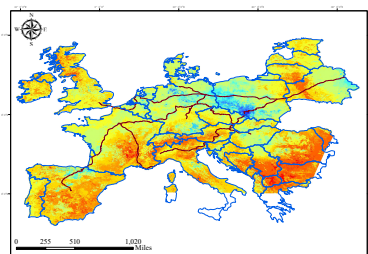

(b)

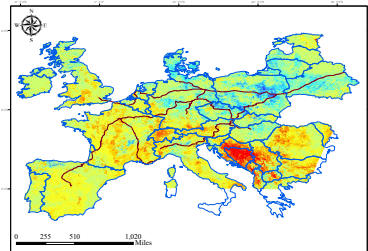

(d)

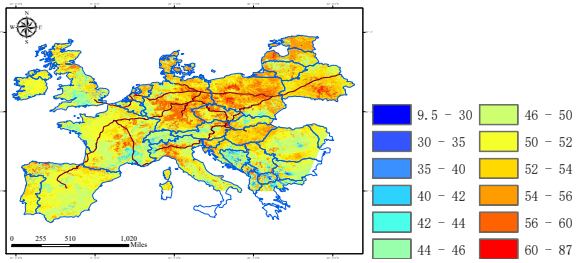

(e)

Fig. 2. CEI derived from 2010 to 2018: (a) 2008-2010, (b) 2010-2012, (c) 2012-2014, (d) 2014-2016, (e) 2016-2018.

\subsection{Mean CEI Values Comparison between S1 and S2}

Fig. 3 and 4 show the mean CEI values, which belong to $\boldsymbol{S} \boldsymbol{I}$ and $\boldsymbol{S} 2$ respectively, with the $\mathrm{X}$-axis showing the countries involved in the different scales, and the Y-axis corresponding to the mean CEI values of different countries. 
Fig. 3 indicates the overall environment condition of the 14 countries along the CER-Express (Europe section) from the year 2010 to 2018. Most of the countries in Fig. 4 are the relatively less developed countries in Europe, which could be used as a standard for the environmental conditions of Europe, due to their better ecological environment compared to the developed countries.

Similarly, to the reports in the references, it was found that the construction of CER-Express had gradually accelerated between 2016 and 2018. As can be seen in Fig. 3, the mean CEI values in $\boldsymbol{S} 1$ during this period showed an overall increasing trend, when compared to the period from 2014 to 2016, which demonstrates the environment degradation between 2016 and 2018. More precisely, the increasing magnitude of CEI values was unprecedented since the construction of CER-Express in the rail-intensive countries, such as Germany (47.18-53.16), Poland (44.77-53.54), as well as small-area countries along the railway, such as Czech Republic (45.19-53.11). On the contrary, in $\boldsymbol{S}$, as shown in Fig. 5, the mean CEI values of most of the countries during 2016 to 2018 showed an overall decreasing trend. The countries with significant decreases in CEI values were Switzerland (52.97-47.35), Serbia (53.09-50.18), Montenegro (54.48-50.02), Albania (52.42-49.12).

The overall upward trend of the CEI values in the countries along the CER-Express and the overall decreasing trend of values in the countries not along the railway during the highspeed construction period from 2016 to 2018, clearly shows environmental degradation in the countries along the CERExpress.

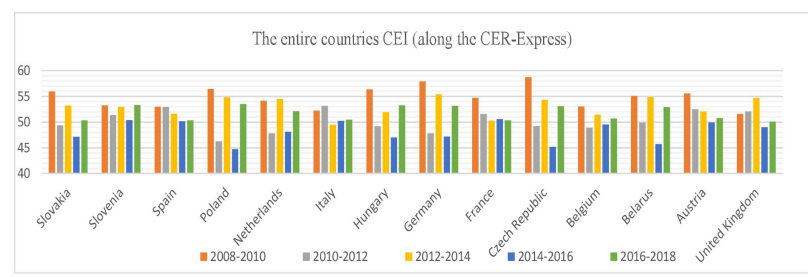

Fig. 3. From 2008 to 2018, the mean CEI values of the countries along the CER-Express Express (European section) were evaluated every two years, with the $\mathrm{X}$-axis corresponding to the countries involved in the area along the route and the $\mathrm{Y}$-axis corresponding to the mean CEI values.

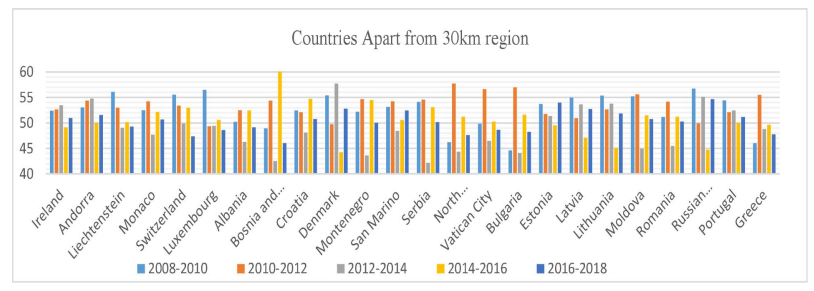

Fig. 4. From 2008 to 2018, the mean CEI values of countries outside the buffer of the CER-Express (European section) were calculated every two years, with the $\mathrm{X}$-axis corresponding to the countries and the $\mathrm{Y}$-axis corresponding to the mean CEI values.

\subsection{Mean CEI Values Comparison from $S 1$ and $S 3$}

Whether the environmental degradation in regions along the CER-Express (Europe section) was caused by its operation or is a result of the general trend for the country was explored by further comparing the magnitude of mean CEI values between $S 1$ and $S 3$

Through observation, the mean CEI values in most of countries of $\boldsymbol{S} 1$ (Fig. 3), sampled every two years, had lower difference values than their corresponding regions in $\boldsymbol{S} 3$. This phenomenon shows the increasing environmental degradation in the buffer zone along the CER-Express may be caused by its operation. Comparing the values in rail-intensive countries and small-area countries along the railways between $\boldsymbol{S} \boldsymbol{1}$ and $\boldsymbol{S} \mathbf{3}$ for an example, the rail-intensive countries, such as Poland and Germany, exhibit the difference of CEI values for two consecutive years in $\boldsymbol{S} 1$ of about 9 and 7 separately, slightly lower than the value of their corresponding regions in $\mathbf{S 3}$. In the small-area countries along the railways, such as Slovakia and Netherland, their difference CEI values in $\boldsymbol{S 1}$ in two consecutive years were around just 4 most of the time. Meanwhile, in $\boldsymbol{S} 3$ the values raised to around 6 most of the time. Therefore, the operation of the CER-Express from 2010 to 2018 had accelerated the environmental degradation to the regions along the CERExpress in most countries.

By analyzing the mean CEI values of $\boldsymbol{S} 3$ (Fig.5) in isolation, most of the CEI values of regions in their own countries along the CER-Express showed continuous fluctuations from 2010 to 2018. During this period, in rail-intensive countries, such as Poland, the difference mean CEI value in two years was up to about 10 most of the time. In lots of small-area countries along the railways, such as Slovakia and Netherland, the CEI difference values also showed the continuous and high fluctuation around 6 between every two years. Thus, disturbance on the ecological vulnerability of the regions along the CER-Express (Europe section) can be seen since the beginning of operation and progressive development of the CER-Express (Europe section).

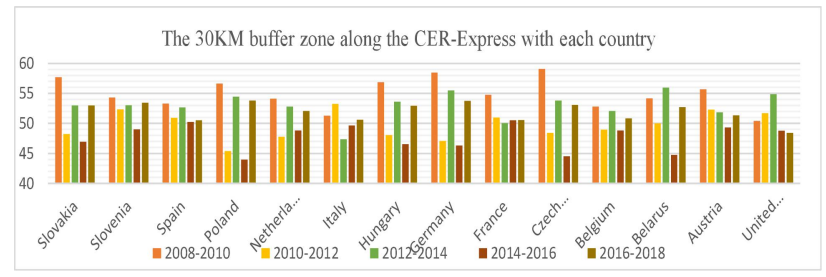

Fig. 5. From 2008-2018, the mean CEI values falling within 30 kilometers buffer zone of CER-Express Express (European section) were calculated every two years, with the $\mathrm{X}$-axis corresponding to the countries involved in the area along the route and the $\mathrm{Y}$-axis corresponding to the mean CEI values.

\section{DISSCUSSION}

In order to determine the specific cause of the environmental degradation in the rail-intensive countries and small-area countries along the railways, difference maps of PM2.5, LST, and normalized NDVI were computed. Those difference maps show the air pollution, the intensity of human activity and the degree of vegetation destruction separately.

The difference maps from 2016 to 2018 were selected as it was the time when CER-Express (Europe section) underwent fast construction and gained rapid development.

In the PM2.5 difference map (Fig. 6a), a high level of air pollution could be found in most of the regions near the CERExpress, such as the regions close to CER-Express from Paris to Madrid, in the rail-intensive countries such as Germany and Poland, northern and eastern Austria as well as in small-area countries along the railways, such as, Hungary, Belarus, Denmark, northern Italy, eastern Czech Republic, etc.

In the LST difference map (Fig. 6b), a high level of human activity, which generated a lot of heat could also be found in some parts of the regions near the CER-Express in Europe, such as northern Spain, and northern Italy. The signs of this could especially be found in rail-intensive countries, such as German, 
north-west Poland, southeast France, northern Austria and within one small-area country along the railways, Czech Republic.

In the VC difference map (Fig. 6c), a low level of the final normalized NDVI difference figures can be observed in a large number of parts of the regions near the CER-Express, particularly the regions in middle and northern Spain and northern Italy. In small-area countries along the railways, such as Czech Republic, southern and eastern Hungary. In railintensive countries, such as Germany, western and eastern part of Poland, northern France, northern and eastern Austria, etc.

The CEI thematic map (Fig. 6d) reveals the environmental condition of the study area from 2016 to 2018. It is worth noting that environmental degradation in most of the rail-intensive countries, such as in Germany, Poland and Austria, as well as along the railways in the Czech Republic, were caused by the integrated influence of air pollution, human activities and vegetation destructions during the construction and operation of the CER-Express. The degradation in other regions and countries along the railways was caused by the impact of one or two factors among the air pollution, human activities and vegetation destructions.

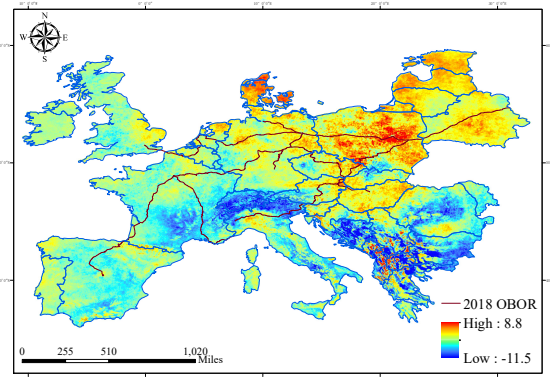

(a)

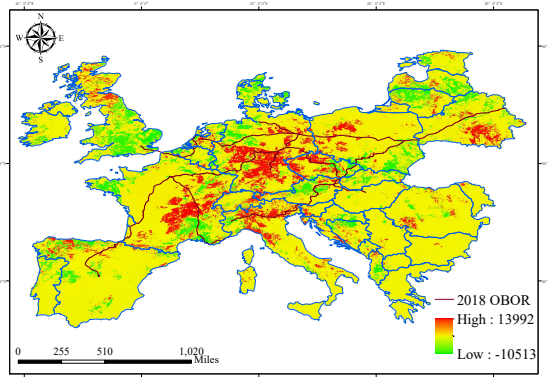

(b)

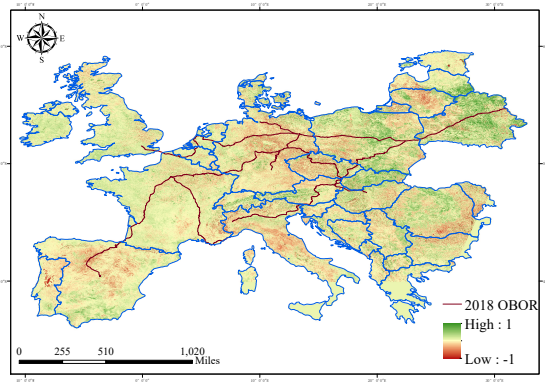

(c)

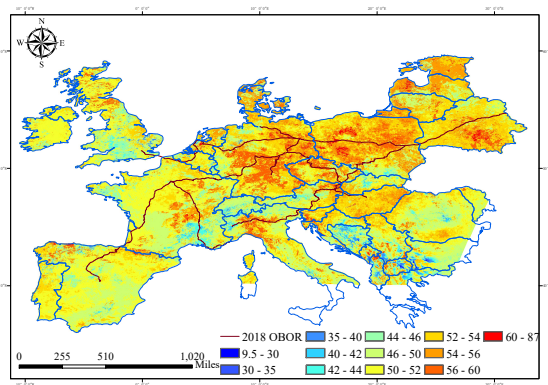

(d)

Fig 6. The difference maps of PM2.5, LST and NDVI during 2016 to 2018 in the study area.

\section{CONCLUSIONS AND FUTURE WORK}

In the study presented, 38 countries located in the European continent were selected as the study area to monitor the ecological changes along the CER-Express (Europe section) during its operation from 2010 to 2018. By integrating longterm remote sensing datasets, a comprehensive evaluation index (CEI) was calculated for the purpose of large scale environment monitoring and CEI maps from 2008 to 2018 in two year intervals. Based on the characteristics of our study area and the route of the CER-Express, the mean CEI values in different regions and countries were calculated at three scales, the entire countries scale, the entire countries-not-along-the-railway scale, and the portion of regions within the $30 \mathrm{~km}$ of CER-Express. Further, histograms of mean CEI values at different scales were compared and analyzed to detect the environmental changes along the CER-Express in the time period from 2008 to 2018.

Our results indicate that a high level of environmental degradation occurred in most of rail-intensive countries and small-area countries along the CER-Express during its fast construction and rapid development from 2016 to 2018 , and the regions along the railways since the beginning of its operation. Meanwhile, we also found disturbance in the ecological vulnerability of the regions along the CER-Express, since the beginning of its operation and during progressive development of the CER-Express. During the fast construction and rapid development of CER-Express from 2016 to 2018, the degradation in most of the rail-intensive countries and one small-area country was found to be caused by the integration of air pollution, human activities and vegetation destructions. The degradation in other regions and countries along the railway in the study area was linked to one or two factors among the air pollution, human activities and vegetation destructions.

In this study, we have conducted a preliminary analysis of the environmental degradation along the CER-Express from 2010 to 2018 using the multi-source dataset and the CEI index. However, the reasons for long-term spatial change in the distribution of CEI in Europe, certain countries and the regions along the CER-Express should be further explored using sociohuman economic datasets.

\section{ACKNOWLEDGEMENTS}

This research was supported by the 2020 China-CEEC Joint Education Project of Institutions of Higher Education (202002), the Pyramid Talent Training Project of Beijing University of Civil Engineering and Architecture (JDYC20200322) and the Fundamental Research Funds for Beijing University of Civil Engineering and Architecture (X20044).

\section{REFERENCES}


Ascensão, Fernando, Lenore Fahrig, Anthony P. Clevenger, Ric hard T. Corlett, Jochen A. G. Jaeger, William F. Laurance, and Henrique M. Pereira. 2018. 'Environmental challenges for the B elt and Road Initiative', Nature Sustainability, 1: 206-09.

Chen, Jing M., Emilio Chuvieco, and Menghua Wang. 2021. 'Pr eface, special issue of "50 years of environmental remote sensin g research: 1969-2019”', Remote Sensing of Environment, 252: 112113

Chen, Mingxing, Yuwen Sui, Weidong Liu, Hui Liu, and Yaohu an Huang. 2019. 'Urbanization patterns and poverty reduction: A new perspective to explore the countries along the Belt and R oad', Habitat International, 84: 1-14.

Fang, Kai, Tingting Wang, Jianjian He, Tijian Wang, Xiaodong Xie, Yiqi Tang, Yang Shen, and Anqi Xu. 2020. 'The distributio $\mathrm{n}$ and drivers of PM2.5 in a rapidly urbanizing region: The Belt and Road Initiative in focus', Science of The Total Environment, 716: 137010 .

Griffiths, Patrick, Benjamin Jakimow, and Patrick Hostert. 2018 'Reconstructing long term annual deforestation dynamics in Par á and Mato Grosso using the Landsat archive', Remote Sensing of Environment, 216: 497-513.

Hafeez, Muhammad, Chunhui Yuan, Wasi Ul Hassan Shah, Mu hammad Tariq Mahmood, Xiaolong Li, and Kashif Iqbal. 2020. 'Evaluating the relationship among agriculture, energy demand, finance and environmental degradation in one belt and one road economies', Carbon Management, 11: 139-54.

He, Chunyang, Bin Gao, Qingxu Huang, Qun Ma, and Yinyin D ou. 2017. 'Environmental degradation in the urban areas of Chin a: Evidence from multi-source remote sensing data', Remote Sen sing of Environment, 193: 65-75.

Kavvada, Argyro, Graciela Metternicht, Flora Kerblat, Naledza ni Mudau, Marie Haldorson, Sharthi Laldaparsad, Lawrence Fri edl, Alex Held, and Emilio Chuvieco. 2020. 'Towards deliverin $\mathrm{g}$ on the Sustainable Development Goals using Earth observatio ns', Remote Sensing of Environment, 247: 111930.
Lu, Linlin, Qihao Weng, Huadong Guo, Suyun Feng, and Qingt ing Li. 2019. 'Assessment of urban environmental change using multi-source remote sensing time series (2000-2016): A compar ative analysis in selected megacities in Eurasia', Science of The Total Environment, 684: 567-77.

Mariano, Denis A., Carlos A. C. dos Santos, Brian D. Wardlow, Martha C. Anderson, Allie V. Schiltmeyer, Tsegaye Tadesse, a nd Mark D. Svoboda. 2018. 'Use of remote sensing indicators to assess effects of drought and human-induced land degradation on ecosystem health in Northeastern Brazil', Remote Sensing of Environment, 213: 129-43.

Meng, Xia, Cong Liu, Lina Zhang, Weidong Wang, Jennifer Sto well, Haidong Kan, and Yang Liu. 2021. 'Estimating PM2.5 con centrations in Northeastern China with full spatiotemporal cover age, 2005-2016', Remote Sensing of Environment, 253: 112203.

Qi, Xiangzhen, Junhe Jia, Huiyu Liu, and Zhenshan Lin. 2019. ' Relative importance of climate change and human activities for vegetation changes on China's silk road economic belt over mult iple timescales', CATENA, 180: 224-37.

Wu, Wenqi, Ming Zhang, and Yueting Ding. 2020. 'Exploring t he effect of economic and environment factors on PM2.5 conce ntration: A case study of the Beijing-Tianjin-Hebei region', Jour nal of Environmental Management, 268: 110703.

$\mathrm{Xu}$, Zhenwei. 2020. 'Summary and Analysis to the operation of CER-Express in 2019'.

https://www.imsilkroad.com/news/p/397878.html.

Yang, Yi, and $\mathrm{Na} \mathrm{Hu.} \mathrm{2019.} \mathrm{'The} \mathrm{spatial} \mathrm{and} \mathrm{temporal} \mathrm{evolution}$ of coordinated ecological and socioeconomic development in th e provinces along the Silk Road Economic Belt in China', Sustai nable Cities and Society, 47: 101466.

Zhang, Xinghua. 2020. 'China-Europe class train sounded the w histle and resumed work with acceleration'. http://www.gov.cn/xinwen/2020-03/22/content 5494092.htm. 